\title{
Белоусов В.Ю.
}

Модели эллиптических конструкций с опущением части сказуемого в кинодиалоге гангстерского фильма

\author{
Belousov V.Yu. \\ Models of elliptical constructions with a part of the predicate \\ elimination in gangster films dialogues
}

В данной статье рассматриваютя модели эллиптических предложений с опущением части сказуемого в кинодиалогах гангстерских фильмов. Автор выделяет и описывает шесть продуктивных моделей эллиптических конструкций в пределах данной группы. Чаще всего опущению подвергаются вспомогательные глаголы to be, to do, to have, a также глагол-связка to be

Ключевые слова: эллиптические предложения, опущение части сказуемого, модели эллиптических конструкций, диалог, гангстерский фильм

Белоусов Владимир Юрьевич

Старший преподаватель

Белгородский государственный национальный исследовательский университет

г. Белгород, ул. Победы, 85
The present article considers models of elliptical sentences with elimination of a part of the predicate in gangster films dialogues. The author distinguishes and analyses six models of elliptical constructions within this group. It should be noted that the linking verb to be or auxiliary verbs to be, to do, to have are eliminated in the part of the predicate position

Key words: elliptical sentences, elimination of a part of the predicate, model of elliptical constructions, dialogue, gangster film

\author{
Belousov Vladimir Yurievich \\ Senior Lecturer \\ Belgorod national research university \\ Belgorod, Pobeda st., 85
}

Рассматривая структурные типы эллиптических предложений в кинодиалоге гангстерского фильма, нами было выделено семь групп эллиптических конструкций: (1) конструкции с опущением подлежащего; (2) с опущением сказуемого; (3) с опущением части сказуемого; (4) с опущением подлежащего и сказуемого; (5) с опущением подлежащего и части сказуемого; (6) другие эллиптические конструкции; (7) с опущением трех и более членов предложения $[1$, c. 24].

В настоящей статье мы проанализируем третью группу эллиптических конструкций - конструкции с опущением части сказуемого - и попытаемся выделить и описать наиболее продуктивные модели построения эллиптических конструкций данной группы. Наш интерес к этой группе оправдан тем, что по частотности реализации она занимает второе место и составляет $21 \%$ всех рассматриваемых эллиптических конструкций. Были выделены следующие модели: 
1. Самая многочисленная модель представляет собой конструкцию с опущением вспомогательного глагола в интеррогативных высказываниях. Стоит отметить, что вспомогательные глаголы в данной модели могут носить разнообразный характер:

a) вспомогательный глагол do в высказываниях в настоящем простом времени, например: (1) You see? They'll be shooting each other like rabbits (Scarface, 1932). (2) You think you're a hard guy? (Little Caesar, 1931).

б) вспомогательный глагол did в высказываниях в простом прошедшем времени, например: (3) Well, it surprise you to hear from me? - Kind of. - I thought it would be kind of nice to have a little talk together (Little Caesar, 1931).

в) вспомогательный глагол to be в высказываниях в настоящем длительном времени, например: (4) You looking for a sock on the button? (5) How much you paying for this stuff? (The Public Enemy, 1931). Как показывают примеры, интеррогативы могут носить как общий, так и специальный характер.

2. В следующей модели построения эллиптических предложений мы также наблюдаем опущение вспомогательного глагола, только теперь уже в констатирующих высказываниях. Здесь можно выделить два варианта:

а) конструкции с опущением вспомогательного глагола to have в высказываниях в настоящем длительно-перфектном времени, а так же в высказываниях в настоящем перфектном времени в пассивном залоге, например: (1) We been cutting each other's throats long enough (Scarface, 1932). (2) I know what you been doing (The public Enemy, 1931). (3) None of us ever been invited up to eat at the Big Boy's dump (Little Caesar, 1931). Строго говоря, здесь мы имеем дело не с полным опущением вспомогательного глагола, а частичным, поскольку всё же часть вспомогательного элемента been эксплицитно присутствует в каждом высказывании и тем самым выражает категорию перфектности, которая выполняет важную роль для обеспечения правильного понимания собеседника и, тем самым, не может быть опущена даже в разговорной речи.

б) конструкция, в которой опущен вспомогательный глагол to be в нарративных высказываниях в простом прошедшем времени в пассивном залоге, например: (4) Four pineapples tossed at us in two days, and the brewery set fire (The Public Enemy, 1932).

В целом, отсутствие вспомогательного глагола, как в интеррогативах, так и в констатирующих высказываниях, можно объяснить второстепенной ролью, которую он выполняет для формирования смысловой составляющей высказывания.

3. Данная модель построения эллиптического предложения описывает конструкцию с опущением глагола-связки to be в настоящем времени в констатирующих и интеррогативных высказываниях, например: (1) Nobody in charge (Scarface, 1932). (2) Smart guy, Rico (Little Caesar, 1931). (3) You afraid of me? (4) You all alone? (Scarface, 1932). Опущение глагола-связки достаточно характерное явление не только для реального диалога, но и для кинодиалога, т.к. наличие подлежащего и именной части сказуемого, речевой ситуации, а в интеррогативах и интонации, достаточно для правильного понимания высказывания. 
4. Следующая модель представляет собой конструкцию с опущением глагола to have в интеррогативных высказываниях с выражениями to have got/ to have got to, например: (1) You got that horse that killed Nails? (The Public Enemy, 1931). (2) What you got there, Joe? (3) We got to go into that again? (Little Caesar, 1931).

5. Менее продуктивная модель построения эллиптических предложений данной группы является конструкция с опущением именной части составного именного сказуемого в реагирующей реплике, например: (1) Is he all right? - He must be (The Public Enemy, 1932). В данном примере мы имеем дело с семантическим эллипсисом, т.к. отсутствующую во втором высказывании именную часть all right можно легко домыслить на основе инициирующей интеррогативной реплики.

6. Последняя модель в этой группе представляет собой конструкцию с опущением инфинитива в составном глагольном сказуемом в реагирующей реплике, например: (1) I don't know nothing about automobiles what's been stolen. Well, you might if some of the bright young men around here had anything to do with it, wouldn't you? (Little Caesar, 1931). Здесь мы также имеем дело с семантическим эллипсисом, поскольку предикат умственной деятельности know в инициирующей реплике, референциально выражен с помощью модального глагола might в реагирующей.

Данные модели эллиптических предложений демонстрируют, что, чаще всего, в качестве опущенной части сказуемого в кинодиалоге гангстерского фильма выступают вспомогательные глаголы (do, did, to be) в интеррогативных высказываниях, вспомогательные глаголы (to have, to be) в констатирующих высказываниях, глагол-связка to be в интеррогативных и констатирующих высказываниях в настоящем времени и глагол to have в высказываниях, содержащих выражения to have got/ to have got to.

\section{Список используемых источников:}

1. Белоусов В.Ю. Структурные типы эллиптических предложений в кинодиалоге гангстерского фильма // Апробация. 2015. №5(32). С. 23-25.

2. Чахоян Л.П. Синтаксис диалогической речи современного английского языка. М.: Высш. школа, 1979. $168 \mathrm{c}$.

(C) 2015, Белоусов В.Ю.

Модели эллиптических конструкций с опущением части сказуемого в кинодиалоге гангстерского фильма
(C) 2015, Belousov V.Yu.

Models of elliptical constructions with a part of the predicate elimination in gangster films dialogues 